\title{
THE PERSONALITY CORRELATES OF ADULTS WHO HAD IMAGINARY COMPANIONS IN CHILDHOOD ${ }^{1,2}$
}

\author{
EVAN KIDD \\ La Trobe University \\ The University of Manchester
}

PAUL ROGERS

University of Bolton
CHRISTINE ROGERS

The University of Manchester

Summary. - Two studies showed that adults who reported having an imaginary companion as a child differed from adults who did not on certain personality dimensions. The first yielded a higher mean on the Gough Creative Personality Scale for the group who had imaginary companions. Study 2 showed that such adults scored higher on the Achievement and Absorption subscales of Tellegen's Multidimensional Personality Questionnaire. The results suggest that some differences reported in the developmental literature may be observed in adults.

An imaginary companion is a vivid imaginary character that is treated as real (Taylor, 1999). They may be invisible, but they may also be toys or dolls that are treated as animate (a personified object). The phenomenon has a long history in the psychological literature. Whereas some early studies associated the phenomenon with negative attributes (e.g., Svendsen, 1934; Ames \& Learned, 1946; Nagera, 1969), subsequent, more controlled studies have identified many positive attributes that are correlated with having an imaginary companion throughout the lifespan.

Children with imaginary companions have a high predisposition to fantasy-based play (Taylor, 1999) and, in general, have been shown on several measures to be highly creative (e.g., Singer, 1961; Schaefer, 1969; Hoff, 2005, but see Pearson, Rouse, Doswell, Ainsworth, Dawson, Simms, et al., 2001). With respect to socio-cognitive development, Taylor and Carlson (1997) showed that 4-year-old children with imaginary companions passed theory-of-mind tasks before same-age peers without imaginary companions. Similarly, Roby and Kidd (2008) showed that 4- to 6-yearold children with imaginary companions outperformed same-age peers on a referential communication task. Since both tasks arguably necessitate adopting the perspective of others, these results suggest that having an imaginary companion is associated with advanced socio-cognitive development. In a review, Taylor (1999) discussed some results that suggest children with imaginary companions have higher IQs than those who do not, although this result has not been consistently replicated.

\footnotetext{
${ }^{1}$ Address correspondence to Evan Kidd, School of Psychological Sciences, La Trobe University, Bundoora 3086, Victoria, Australia or e-mail (e.kidd@latrobe.edu.au).

${ }^{2}$ We thank Claire Brown, Kirsty Grant, and Thomas Hey for help with data collection; Richard Brown for providing us with materials; and Ross Day for enlightened discussion.
} 
The phenomenon is not limited to young children. Seiffge-Krenke $(1993,1997)$ reported on the imaginary companions of adolescents ages 12 to 17 years. By analysing diary entries, she identified that, in comparison to peers who did not have an imaginary companion, the adolescents who mentioned them in their writing had (i) a greater propensity to daydream, (ii) better coping strategies by means of social resources (e.g., by being more inclined to ask for help), and (iii) more positive self-esteem. Simply keeping a diary was associated with general satisfaction with self and friends, self-disclosure, better perspective-taking, and higher creativity.

Other studies have shown that having an imaginary companion in childhood is correlated with personality characteristics and career choices in adulthood. Gleason, Jarudi, and Cheek (2003) found that women who recalled having an imaginary companion in childhood scored higher than did women who did not on self-report measures of imagination and on personality scales measuring dependent interpersonal styles and internalstate awareness. Myers (1979) suggested adults who had imaginary companions as children tended to seek careers in the creative arts. Similarly, Taylor, Hodges, and Kohanyi (2003) reported that more creative writers recalled having an imaginary companion than the normal population. Although the general consensus is that there are more similarities than differences between those who have had or those who did not have an imaginary companion, these data suggest that having had one may be associated with creativity and some personality traits.

The current paper reports two studies which add to this literature. Study 1 concerned whether adults who reported having an imaginary companion as a child scored higher on a measure of creativity than those who did not. Study 2 concerned associations of certain personality traits for such groups.

\section{STUdy 1}

Although adults who work in creative professions may be more likely to have had an imaginary companion as a child, no study has tested adults using a psychometric test of creativity. Further, the data from the developmental literature are equivocal. In the most comprehensive study of creativity and its association with imaginary friends, Hoff (2005) reported that children who have an imaginary companion scored higher on two out of three measures of creativity than did children without one. Singer (1961) and Schaefer (1969) also found children with imaginary companions were more creative (cf. Pearson, et al., 2001). In contrast, although Seiffge-Krenke (1997) found that adolescents who kept diaries scored higher on the Torrance Test of Creativity (Torrance, 1969) than did adolescents who did not keep diaries, she did not find creativity was associated with having an imaginary companion. The potential confound of this study was that keep- 
ing a diary was a necessary condition for having an imaginary companion. This is limiting, as one could argue that keeping a diary is a behaviour qualitatively similar to having an imaginary companion. Therefore, whether having had an imaginary companion is associated with higher creativity later in life is unclear, so in Study 1 the hypothesis was that adults who reported having an imaginary companion as a child would score higher on a test of creativity than those who did not have one as a child.

\section{Method}

Participants. - First-year undergraduate students $(N=283)$ in psychology from the University of Bolton and The University of Manchester in Northern England participated as part of a laboratory class requirement ( $n=218,77 \%$ of the group were women; $n=65,23 \%$ were men). The study was approved by the human ethics committees of both universities, and all participants gave informed consent to participate, but were unaware of the hypothesis of the study. Seventy-three of the 283 participants $(25.8 \%)$ indicated that they had an imaginary companion as a child. This is comparable to results reported by Gleason, et al. (2003).

Materials and procedure.-Participants completed the Gough Creative Personality Scale (Gough, 1979). On the test the participants indicated whether 30 adjectives accurately described them ("yes/no"). There are 18 positive and 12 negative items. Participants receive one point $(+1)$ for every positive item to which they respond "yes" and minus $1(-1)$ for every negative item. The scale has good internal consistency, with alpha coefficients ranging from .73 to .81, depending on the sample. The internal consistency for the current sample was good (Cronbach's $\alpha=.77$, MacDonad's $\omega_{h}=.72$ ). Gough (1979) reported that test scores correlate well with other measures of creativity (e.g., Domino's 1970 Adjective Check List, $r=.68$; Smith \& Schaefer's 1969 adjective checklist, $r=.74$ ).

Imaginary companion status was ascertained by means of an additional short questionnaire that asked if the participants had an imaginary companion as a child. The questionnaire asked for general demographic information (e.g., age, sex, ethnicity), whether the participant had an imaginary companion as a child and, if so, various questions about the characteristics of the companion (e.g., name, type of companion, gender, age, physical characteristics).

\section{Results and Discussion}

The participants who recalled having an imaginary friend $(M=5.8$, $S D=4.4$ ) as a child scored higher on the Gough Creative Personality Scale than the participants who did not have one $(M=3.9, S D=3.8)$. This difference was significant $\left(t_{281}=3.21, p=.001, d=0.38,98 \% C I=.5,3.2\right)$, supporting the hypothesis that adults who recalled having imaginary companions 
as children would score higher on a test of creativity than adults who did not. There were no sex differences in the sample.

These data suggest that having a recollection of an imaginary companion in childhood is associated with higher creativity in adults. This is consistent with the observation that such children score higher on tests of creativity than children without imaginary companions (Singer, 1961; Schaefer, 1969; Hoff, 2005), and the observation that adults in creative professions such as creative writing are more likely than members of the general population to have had an imaginary companion in childhood (Taylor, et al., 2003).

Creativity is a complex concept with several operational definitions, so it is instructive to consider the nature of the observed difference. The Gough Creative Personality Scale (Gough, 1979) requires participants to rate themselves on a list of descriptive adjectives; therefore, this scale measures personality characteristics associated with creativity. Studies that have not reported a group difference have not used personality assessments, but instead used performance based fluency measures (SeiffgeKrenke, 1997; Pearson, et al., 2001). Future research designed to test participants on a range of measurements is required before drawing any strong conclusions from these data.

\section{STUDY 2}

Study 2 investigated whether a separate group of undergraduate students differed on certain personality dimensions depending on whether they had an imaginary companion in childhood. Only one study has explicitly investigated the personality correlates of having an imaginary companion in childhood. Gleason, et al. (2003) tested 102 female university students on a set of measures of imagination and personality. Those students who had memories of imaginary companions in childhood differed from those who did not on some of the measures: imagery use, hostile daydreams, and vivid night dreams. These participants also scored significantly higher on a composite measure created by entering all seven measures of imagination into a factor analysis. Those who had imaginary companions as children also scored higher on their interpersonal style toward others, and on internal state awareness, which is consistent with the finding that children with imaginary companions tend to be socially oriented and accommodating (e.g., Manosevitz, Fling, \& Prentice, 1977; Singer \& Singer, 1990; Seiffge-Krenke, 1997).

Taylor, et al. (2003) reported that creative writers, a large percentage of whom had imaginary companions as children, scored higher than the general population on the four subscales of the Interpersonal Reactivity Index (Davis, 1983), which measures predisposition to fantasy, perspective taking, empathic concern, and personal distress. Such findings are 
consistent with the social orientation associated with a keen imaginative life. The writers also had a high mean score on the Dissociative Experiences Scale (Bernstein \& Putnam, 1986), particularly on the Absorption subscale, which measures people's tendency to become highly engrossed in activities.

In Study 2, a new cohort of adults were given a more comprehensive personality inventory to assess personality dimensions. Three personality dimensions were identified on which adults who have memories of imaginary companions are likely to differ from those who did not have one. The first dimension we identified was the tendency to be absorbed in an active imaginative life (i.e., Absorption). There is evidence which supports the observation that children and adolescents who have imaginary companions and adults who have such memories engage in active imagining and play (Ames \& Learned, 1946; Singer, 1961; Mauro, 1991; Seiffge-Krenke, 1997; Bouldin \& Pratt, 1999; Gleason, et al., 2003; Roby \& Kidd, 2008). The first hypothesis was that college students who reported memory of an imaginary companion would also have high scores.

The second dimension was Achievement. Two studies have shown that children with imaginary companions demonstrate sustained attention, in comparison to children without one on a waiting task (Singer, 1961; Mauro, 1991). Other studies suggest that children with imaginary companions score higher on measures of socio-cognitive achievement in comparison to their peers; in particular, theory-of-mind and referential communication (Taylor \& Carlson, 1997; Roby \& Kidd, 2008). The second hypothesis was that adults who have memories of imaginary companions as children would score higher on a measure of predisposition toward achievement than would peers who did not report an imaginary companion.

The third dimension related to Social Orientation. Children with imaginary companions have been shown to be socially oriented (Partington \& Grant, 1984). Similarly, as adolescents they seek out social relations as a coping mechanism in times of stress (Seiffge-Krenke, 1997). Finally, as adults they score higher on measures of interpersonal style, suggesting that social interaction is important to them (Gleason, et al., 2003). The third hypothesis was that adults who had imaginary companions as children would score higher on a measure of social closeness than adults who did not report one.

Method

Participants. - Undergraduate students from The University of Manchester participated ( $N=149 ; 118$ women, 31 men). The study was approved by the human ethics committees of The University of Manchester, and all participants gave informed consent to participate. Forty-two of the respondents indicated that they had a memory of an imaginary compan- 
ion, constituting $28.2 \%$ of the sample. They were unaware of the aims and hypotheses of the study, and had not participated in Study 1.

Materials and procedure.-The participants completed the Multidimensional Personality Questionnaire (Tellegen, 1982), a comprehensive 300 item factor-analytically developed personality inventory with 11 subscales which measure primary personality dimensions. The 11 dimensions are: Well-being, Social Potency, Achievement, Social Closeness, Stress Reaction, Alienation, Aggression, Control, Harm Avoidance, Traditionalism, and Absorption. Each dimension has high internal consistency, with alpha coefficients between .77 and .90 . The items are statements to which the respondent must answer 'true' or 'false' (for more information see Tellegen, 1982, p. 8). The three hypotheses are related to the following three dimensions.

1. Absorption: high scores suggest emotional responsiveness to engaging sights and sounds, a tendency to be captured by entrancing stimuli and to become absorbed in vivid and compelling recollections and imaginings. An example of an item measuring absorption is "I can be greatly moved by eloquent or poetic language." For the current sample, Cronbach's $\alpha=.89$ and MacDonald's $\omega_{h}=.76$.

2. Achievement: high scores suggest a propensity to work hard and enjoy long hours and demanding projects. An example of an item is "I often keep working on a problem even when I am very tired." Cronbach's $\alpha=.85$ and MacDonald's $\omega_{h}=.73$.

3. Social Closeness: high scores on this scale are indicative of sociability, close interpersonal ties, and a propensity to turn to others for comfort and help. An example of an item is "I usually like to spend time with friends rather than alone." In this sample, Cronbach's $\alpha=.86$ and MacDonald's $\omega_{h}=.71$.

Imaginary companion status was measured using the same questionnaire used in Study 1.

\section{Results and Discussion}

Table 1 shows the scores on the three personality dimensions for the two groups. The imaginary companion group scored higher than the group without imaginary companions on the Absorption and Achievement subscales, but the groups did not differ on the Social Closeness subscale. No sex differences were observed. In the interest of completeness the two groups were compared on the personality dimensions for which there were no hypotheses, as also shown in Table 1 . No significant differences were observed.

Two of the three hypotheses were supported: adults who had imaginary companions as children scored significantly higher than those who did not have one on the Absorption and Achievement subscales. The fact that they scored higher on the Absorption subscale is consistent with the 
TABLE 1

Means, Standard Deviations, $t$ Ratios, Effect Sizes, and 98\% Confidence InTervals of Groups With and Without Imaginary Companions

\begin{tabular}{|c|c|c|c|c|c|c|c|c|}
\hline \multirow[t]{2}{*}{ Measure } & \multicolumn{2}{|c|}{$\begin{array}{l}\text { Imaginary } \\
\text { Companion }\end{array}$} & \multicolumn{2}{|c|}{ No Companion } & \multirow[t]{2}{*}{$t$} & \multirow[t]{2}{*}{$p$} & \multirow[t]{2}{*}{$d$} & \multirow[t]{2}{*}{$98 \% C I$} \\
\hline & M & $S D$ & M & $S D$ & & & & \\
\hline Achievement & 12.4 & 4.2 & 10.5 & 4.5 & 2.40 & $.02^{*}$ & .40 & $.05,3.8$ \\
\hline Absorption & 20.4 & 7.4 & 16.0 & 7.8 & 3.10 & $.002 \dagger$ & .52 & $1.1,7.7$ \\
\hline Social Closeness & 16.4 & 4.1 & 16.7 & 3.4 & 0.55 & .59 & .09 & $-1.9,1.2$ \\
\hline Well-being & 17.2 & 6.1 & 16.7 & 5.5 & 0.51 & .61 & .08 & $-1.9,3.0$ \\
\hline Social Potency & 12.3 & 5.2 & 12.4 & 5.7 & 0.04 & .97 & .01 & $-2.4,2.3$ \\
\hline Stress Reaction & 15.5 & 6.0 & 14.6 & 9.8 & 0.54 & .59 & .09 & $-2.9,4.7$ \\
\hline Alienation & 4.9 & 3.5 & 4.4 & 3.7 & 0.73 & .47 & .12 & $-1.1,2.0$ \\
\hline Aggression & 5.7 & 5.7 & 6.3 & 6.3 & 0.95 & .34 & .16 & $-2.3,1.0$ \\
\hline Control & 15.0 & 7.7 & 12.8 & 5.5 & 1.90 & .06 & .31 & $-.5,4.8$ \\
\hline Harm Avoidance & 17.7 & 8.3 & 17.5 & 5.3 & 0.20 & .85 & .03 & $-2.5,2.9$ \\
\hline Traditionalism & 16.6 & 4.9 & 15.5 & 4.3 & 1.30 & .21 & .21 & $-.9,2.9$ \\
\hline
\end{tabular}

${ }^{*} p<.05 .+p<.01$.

finding that adults who report having an imaginary companion in childhood still have an active imaginative life (Gleason, et al., 2003), and with Taylor, et al.'s finding (2003) that creative writers score highly on a similar measure. This trait appears to be the dimension that most marks this group, and so it is instructive to consider what this result means in more detail.

Tellegen (1992) discussed the Absorption subscale in some detail, pointing out the scale "appears to represent a disposition to enter ... psychological states that are characterised by marked restructuring of the phenomenal self and world. These more or less transient states may have a dissociated or an integrative and peak-experience-like quality" (p. 1). Scores correlate positively with measures of hypnotic responsiveness (Roche \& McConkey, 1990). Such an effect is consistent with the finding that dissociative experiences are related to fantasy proneness (Giesbrecht, Merckelbach, Kater, \& Sluis, 2007), and Taylor, et al.'s observation (2003) that creative writers score higher than the average on some measures of dissociation. However, it is important to point out that a high score on Absorption in normal adults is not always related to abnormal psychological functioning. Taylor, et al. reported that the creative writers in their sample scored highest on the subscale of the Dissociative Experiences Scale which measured absorption, the subscale least likely to be related to psychopathology. Similarly, while Klinger, Henning, and Janssen (2009) reported that while scores high in dissociative thinking are weakly related to psychopathology, activities typically associated with absorption, such as daydreaming, are not (see also Merckelbach, Horselenberg, \& Muris, 2001; Giesbrecht, Lynn, Lilienfeld, \& Merckelbach, 2008). 
There was also a difference on the Achievement subscale, consistent with the observation in the developmental literature that having an imaginary companion in childhood is associated with facilitated socio-cognitive development and an ability to concentrate for longer periods (Singer, 1961; Mauro, 1991; Taylor \& Carlson, 1997; Roby \& Kidd, 2008).

In contrast, there was no difference between the two groups on the Social Closeness subscale. The result is inconsistent with data reported by Gleason, et al. (2003), who showed that their group of women who had imaginary companions as children scored higher on a measure of interpersonal style toward others than did women who did not have imaginary companions. It is also inconsistent with the general observation that children with imaginary companions are rated by their parents as outgoing (Roby \& Kidd, 2008), and that adolescents with imaginary companions actively seek out social connections (Seiffge-Krenke, 1997). One possible reason for the difference between this result and that of Gleason, et al. is that the Multidimensional Personality Questionnaire's Social Closeness subscale might be too coarse a measure to capture any difference. Gleason, et al. included three measures of interpersonal style: (i) toward others, (ii) away from others, and (iii) against others, and reported a group difference for (i) only. Thus, the more refined category of "interpersonal style toward others" may better capture any differences in sociability between the groups.

\section{General Discussion}

The present results suggest that traits associated with the presence of an imaginary companion in childhood may be in evidence on tests in adulthood. The group of adults who recall having an imaginary companion as a child scored higher than the group that did not on measures of creativity, absorption, and achievement. These results complement past research that has also identified associations between the childhood phenomenon of imaginary companions and adult personality (Myers, 1979; Gleason, et al., 2003; Taylor, et al., 2003).

These data raise a number of issues. Firstly, the fact the two groups in Study 2 differed on only two out of 11 personality traits suggests that the groups were more similar than different. This is consistent with the experience of imaginary companions in childhood as not indicating psychopathology (Taylor, 1999). Secondly, since the groups differed on mostly positive dimensions, the data show that the experience of an imaginary companion is a positive one. One possible exception is the fact that heightened absorption is not always positive. Future research should aim to clarify the exact nature of the tendency for adults who have memories of imaginary companions to score high on absorption.

Cross-sectional individual differences studies such as the current one 
are limited to inference of developmental phenomena based on correlations. Therefore, no firm claims can be made about how having an imaginary companion leads to the observed group differences. Furthermore, the sample was biased because the study relied on retrospective report. However, the data do lay the foundation for future studies to tease out the source of the observed differences. For instance, the results from the present study could be replicated with additional and alternative measures, and longitudinal data would be particularly illuminating. Overall, the phenomenon of imaginary companions is an intriguing one that would benefit from more intense study. The emerging picture is that the invention of imaginary companions is associated with some specific and largely positive behaviours, experiences, and personality traits. However, the picture is far from complete, and further studies are needed.

\section{REFERENCES}

Ames, L., \& LeArned, J. (1946) Imaginary companions and related phenomena. Journal of Genetic Psychology, 69, 147-167.

Bernstein, E. M., \& Putnam, F. W. (1986) Development, reliability, and validity of a dissociation scale. The Journal of Nervous and Mental Disease, 174, 727-735.

Bouldin, P., \& Pratt, C. (1999) Characteristics of preschool and school-age children with imaginary companions. Journal of Genetic Psychology, 160, 397-410.

Davis, M. H. (1983) Individual differences in empathy: evidence for a multidimensional approach. Journal of Personality and Social Psychology, 44, 113-126.

Domino, G. (1970) Identification of potentially creative persons from the Adjective Check List. Journal of Consulting and Clinical Psychology, 35, 48-51.

Giesbrecht, T., Lynn, S. J., Lilienfeld, S. O., \& Merckelbach, H. (2008) Cognitive processes in dissociation: an analysis of core theoretical assumptions. Psychological Bulletin, 134, 617-647.

Giesbrecht, T., Merckelbach, H., Kater, M., \& Sluis, A. (2007) Why dissociation and schizotypy overlap: the joint influence of fantasy proneness, cognitive failures, and childhood trauma. Journal of Mental and Nervous Disease, 195, 812-818.

GleAson, T. R., JARudi, R. N., \& CHeEK, J. M. (2003) Imagination, personality, and imaginary companions. Social Behavior and Personality, 31, 721-738.

Gough, H. R. (1979) A creative personality scale for the Adjective Check List. Journal of Personality and Social Psychology, 37, 1398-1405.

Hoff, E. (2005) Imaginary companions, creativity, and self-image in middle childhood. Creativity Research Journal, 17, 167-180.

Klinger, E., Henning, V. R., \& Janssen, J. M. (2009) Fantasy-proneness dimensionalized: dissociative component is related to psychopathology, daydreaming as such is not. Journal of Research in Personality, 43, 506-510.

Manosevitz, M., Fling, S., \& Prentice, N. M. (1977) Imaginary companions in young children: relationships with intelligence, creativity, and waiting ability. Journal of Child Psychology and Psychiatry, 18, 73-79.

Mauro, J. (1991) The friend that only I can see: a longitudinal investigation of children's imaginary companions. Unpublished doctoral dissertation, Univer. of Oregon, Eugene. 
Merckelbach, H., Horselenberg, R., \& Muris, P. (2001) The Creative Experiences Questionnnaire (CEQ): a brief self-report measure of fantasy proneness. Personality and Individual Differences, 31, 987-995.

Myers, W. A. (1979) Imaginary companions in childhood and adult creativity. Psychoanalytic Quarterly, 48, 292-307.

Nagera, H. (1969) The imaginary companion: its significance for ego development and conflict solution. Psychoanalytic Study of the Child, 24, 165-195.

Partington, J., \& Grant, C. (1984) Imaginary playmates and other useful fantasies. In P. Smith (Ed.), Play in animals and humans. New York: Basil Blackwell. Pp. 217-240.

Pearson, D., Rouse, H., Doswell, S., Ainsworth, C., Dawson, O., Simms, K., Edwards, L., \& Faulconbridge, J., (2001) Prevalence of imaginary companions in a normal child population. Child: Care, Health, and Development, 27, 13-22.

Roвy, A. C., \& Kidd, E. (2008) The referential communication skills of children with imaginary companions. Developmental Science, 11, 531-540.

Roche, S. M., \& McConkey, K. M. (1990) Absorption: nature, assessment, and correlates. Journal of Personality and Social Psychology, 59, 91-101.

SchAefer, C. E. (1969) Imaginary companions and creative adolescents. Developmental Psychology, 1, 747-749.

SeIfFGe-KRENKe, I. (1993) Close friendship and imaginary companions in adolescence. New Directions for Child Development, 60, 73-87.

SEIFFGE-KRENKE, I. (1997) Imaginary companions in adolescence: sign of a deficient or positive development. Journal of Adolescence, 20, 137-154.

Singer, D. G., \& Singer, J. L. (1990) The house of make believe: children's play and the developing imagination. Cambridge, MA: Harvard Univer. Press.

SiNGER, J. (1961) Imagination and waiting ability in young children. Journal of Personality and Social Psychology, 29, 396-413.

Smith, J. M., \& Schaefer, C. E. (1969) Development of a creativity scale for the adjective Check List. Psychological Reports, 25, 87-92.

Svendsen, M. (1934) Children's imaginary companions. Archives of Neurology and Psychiatry, 32, 985-999.

TAYLOR, M. (1999) Imaginary companions and the children who create them. New York: Oxford Univer. Press.

TAYLOR, M., \& CARlson, S. (1997) The relation between individual differences in fantasy and theory of mind. Child Development, 68, 436-455.

Taylor, M., Hodges, S. D., \& Kohanyi, A. (2003) The illusion of independent agency: do adult fiction writers experience their characters as having minds of their own? Imagination, Cognition, and Personality, 22, 361-380.

Tellegen, A. (1982) Brief manual for the Multidimensional Personality Questionnaire. Unpublished manuscript, Univer. of Minnesota, Minneapolis.

Tellegen, A. (1992) Note on structure and meaning of the MPQ Absorption Scale. Unpublished manuscript, Univer. of Minnesota, Minneapolis.

Torrance, P. E. (1969) Curiosity of gifted children and performance on timed and untimed tests of creativity. Gifted Child Quarterly, 13, 155-158. 